\title{
Diffuse tracheo-bronchial amyloidosis: a rare variant of a protean disease
}

\author{
C. B. PROWSE AND R. I. K. ELLIOTT \\ From the Royal Sussex County Hospital, Brighton
}

In 1958 one of us (C.B.P.) reviewed a series of cases in which amyloid deposits occurred exclusively in the lower respiratory tract. Most of the patients had diffuse infiltration of the trachea and bronchial passages with amyloid material deposited under an intact mucosa in a manner to cause intrinsic narrowing. The designation 'diffuse tracheo-bronchial amyloidosis' was suggested for this condition, of which two new examples were described. One patient had died before the 1958 paper was published, though no necropsy had been obtained; here we report the death of the second patient and give a detailed account of the necropsy findings.

\section{CASE REPORT}

A married woman aged 47 was first seen at the Royal Sussex County Hospital in April 1949 when she complained of wheezing and difficult breathing, but these symptoms and variable aphonia had already been present on and off for nine years. The diagnosis of amyloid disease was made in 1952 when severe dyspnoea and stridor called attention to an amyloid tumour in the larynx and in 1953 led to the discovery of diffuse tracheo-bronchial amyloid infiltration for which tracheostomy became necessary. Thereafter bronchial infection precipitated episodes of acute respiratory distress with pronounced stridor at least once a year between 1953 and 1958, and the airways narrowed progressively in spite of piecemeal removal of amyloid material on more than one occasion. Haemoptysis occurred during one 48-hour period, and lobar collapse was observed in both lungs from time to time, that in the right lower lobe being notably persistent.

Clinical examination revealed no evidence of amyloid disease elsewhere in the body, proteinuria was not observed, and the blood picture and sedimentation rate were normal. Marrow biopsy was negative. The serum protein figures were normal, and the electrophoretic pattern was only once disturbed by slight gamma globulin excess. The Congo red absorption test was negative.

No change in the general condition was observed at her occasional out-patient attendances during 1958, and her weight remained steady. She was given $250 \mathrm{mg}$. tetracycline twice a day in the winter months $\mathcal{N}^{\circ}$ to check minor bronchopulmonary infections, and she $\mathrm{O}$ occasionally required oxygen to relieve dyspnoea and cyanosis. Respiratory distress did not become severe until April 1959 when a throat infection led to acute bronchitis, complicated by haemoptysis of about $1 \mathrm{oz}$. and a 'suffocation attack'. She recovered at home in about six weeks, but when seen again at hospital she had lost $5 \mathrm{lb}$. in weight and stridor had increased; wheezes were numerous in both lungs and there was partial atelectasis of the lower lobe of the right lung.

In October 1959 she was admitted to hospital for the last time in another attack of acute bronchitis which had not responded to tetracycline at home. Bronchospasm and retained secretions were causing dyspnoea, central cyanosis, and severe distress, though there was no massive pulmonary collapse or consolidation. Isoprenaline inhalations and Choledyl by mouth eased her breathing, but on the day following admission she complained of severe pain in the chest, and 36 hours later, confused and exhausted by respiratory obstruction and infection, she collapsed and died suddenly.

\section{NECROPSY FINDINGS}

The body, examined 14 hours after death, was that of a small, thin, old-looking woman of 58 with a patent tracheostomy.

There was slight senile cortical atrophy of the brain and well-marked atheroma in the tributary vessels of the circle of Willis. The tongue was normal and the ears and nasal sinuses were free $\mathscr{O}$ from infection. There were no amyloid deposits $N$ in the brain, meninges, mouth, or nasopharynx.

The epiglottis and the true and false vocal cords 0 were normal and without amyloid deposits, but $1 \mathrm{~cm}$. below the cords warty amyloid outgrowths $\stackrel{\odot}{\mathscr{D}}$ were present on the anterior laryngeal wall, and $\stackrel{?}{?}$ in the trachea they formed a confluent mass $\square$ beneath the mucous membrane. Amyloid was ${ }_{0}^{\circ}$ thickly deposited at the tracheostomy where it had $\stackrel{\odot}{\mathbb{D}}$ moulded the tube and seemed to occlude the $\overrightarrow{\mathbb{D}}$ trachea above; the mucous membrane of the 
trachea below the stoma showed pressure changes with ulceration and below this again it was grossly thickened and partly covered by yellow exudate. A submucous sheet of amyloid lined the trachea throughout its whole length and extended into the main bronchi (Fig. 1).

The two lungs were treated differently to demonstrate the changes present. With care to avoid over-distension, the left was fixed rapidly by injecting formol saline (10\% formaldehyde) into the bronchial tree and the pulmonary artery through a fine polythene catheter; it was then immersed in formol saline, and vertical (coronal) sections 1-2 cm. thick were cut after 24 hours. Fixation of each was completed individually and some were stained with Congo red, others with iodine; the former gave more satisfactory results.

The main bronchi and their major divisions were the only ones affected, but in these the deposits were massive and caused extreme narrowing (Fig. 2). In the left lung the transition to normal was abrupt at the division of lobar into lobular branches, and none of the more peripheral parts of the bronchial tree contained any amyloid deposits. Thus the stem bronchi to upper and lower lobes were affected, the former as far as the points of division of the main and lingular portions into their respective lobular branches and

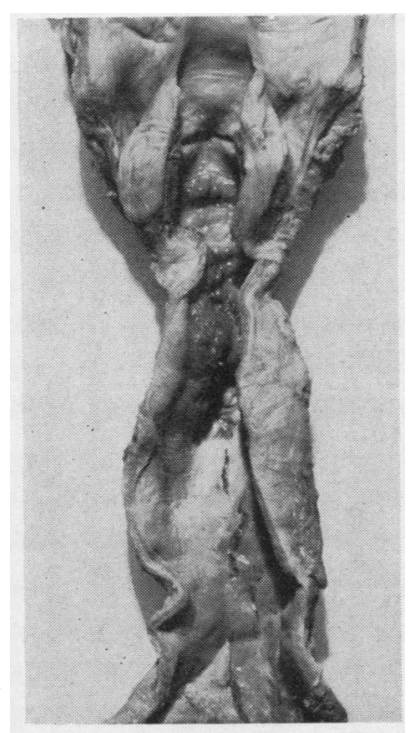

FIG. 1. Larynx and trachea, opened along the posterior wall, showing gross distortion and thickening due to amyloid deposition. The tracheostomy opening is hidden, but the track of the tube is seen as a white oblique scar in the centre of the trachea, overhung by a dark mass of amyloid.

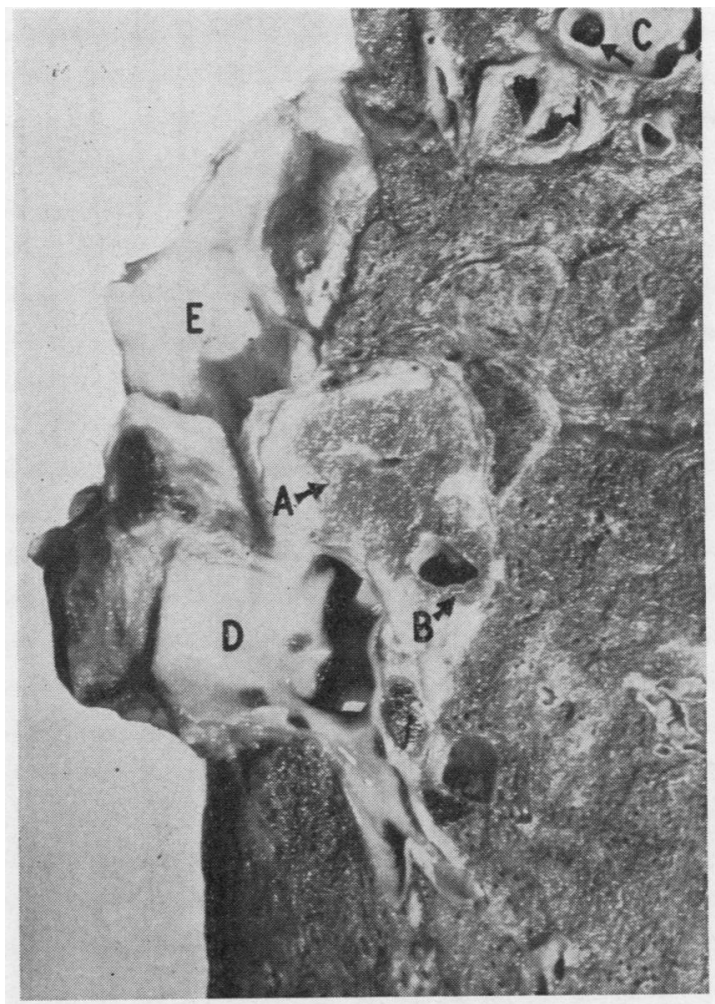

FIG. 2. Left lung, coronal section. The almost completely occluded main bronchus is in the centre, a mass of amyloid surrounding the slit-like lumen $(A)$; the lower lobe bronchus running from it $(B)$ has a wider lumen. At the top of the picture is a pulmonary artery occluded by a clot $(C)$; beneath and to the left is a plaque of amyloid in a smaller bronchus. $(D)$ is the pulmonary artery and $(E)$ the pulmonary vein.

the latter to levels just within the orifices of the apical lower and the three basal segmental bronchi. There were areas of consolidation in the inferior segment of the lingula and the anterior basal segment of the left lower lobe. There were antemortem clots, without evidence of infarction and therefore probably terminal, in medium calibre arteries of the left lower lobe.

The right lung was radiographed uncut after Micropaque had been injected by easy stages into the bronchial tree; later it was fixed and sliced transversely. Fusiform bronchiectasis was demonstrated in the right lower lobe which was connected to the proximal part of the bronchial tree by a thread of opaque substance representing its narrowed stem bronchus (Fig. 3). As in the left lung, the amyloid was deposited only in the major bronchi and their principal divisions. The 


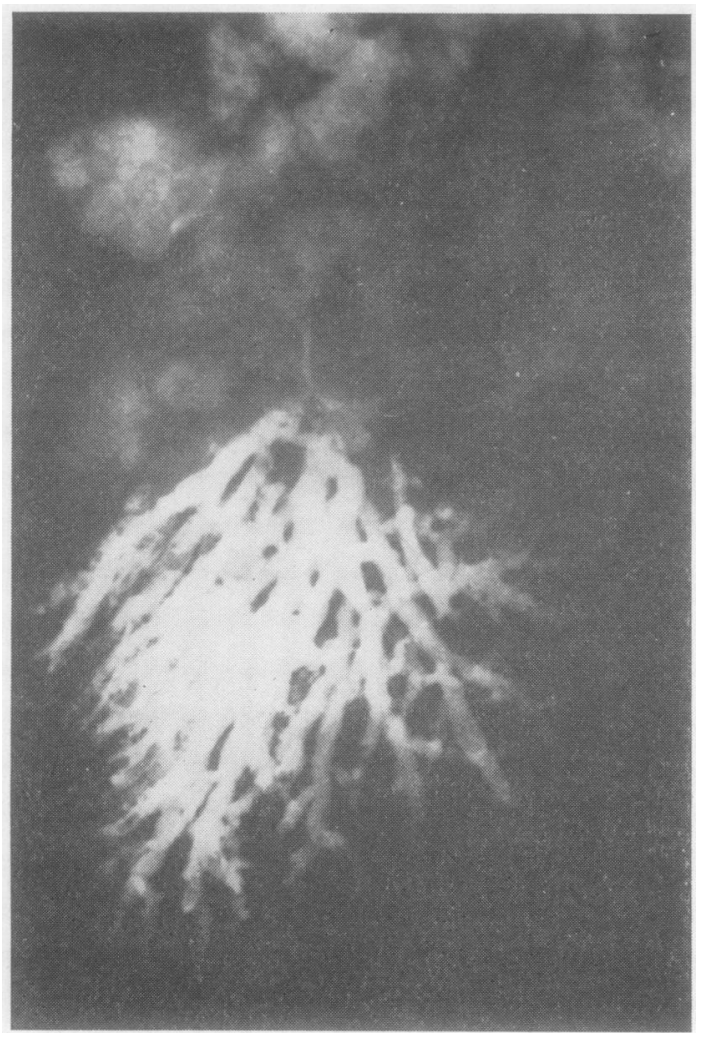

FIG. 3. Radiograph of necropsy specimen of right lung? the bronchial tree injected with Micropaque. Above the grossly bronchiectatic lower lobe a thin shadow shows the extreme degree of narrowing of the lower lobe bronchus.

upper lobe was well aerated, but the bronchiectasis in the lower lobe was associated with diffuse consolidation. No amyloid deposits could be seen $\overrightarrow{.}$ macroscopically in its dilated bronchi.

A large coiled antemortem clot filled the mair pulmonary artery and extended into its major branches, but this had not caused infarction ando its lodgment was clearly a terminal event. The heart was normal in size and the chambers and valves were normal. The coronary arteries? particularly the descending branch of the left ${ }_{2}$ were narrowed by atheroma, but nowhere occluded; the aorta was slightly atheromatous No amyloid deposits were present in these vessels $\frac{\mathbb{D}}{3}$ The gastrointestinal tract, the liver, spleen, ando pancreas were normal, also the suprarenal glands and the kidneys, ureters, bladder, and urethra $\vec{\varnothing}$ the internal and external genitalia were small and the ovaries atrophic. No amyloid deposits werø present in any of these organs. Clots were present in the calf veins of both legs and in the right popliteal and femoral veins up to mid-thigh levelo No amyloid deposits were found in the skin or in the subcutaneous tissues, blood vessels, or nerves of either limb.

FIG. 4. Glands in the submucosa of a bronchus undergoing conversion to amyloid ghosts. Plasma cells, some of which are arrowed, are scattered in the connective tissue septa between them. $H$. and $E$., $\times 400$.

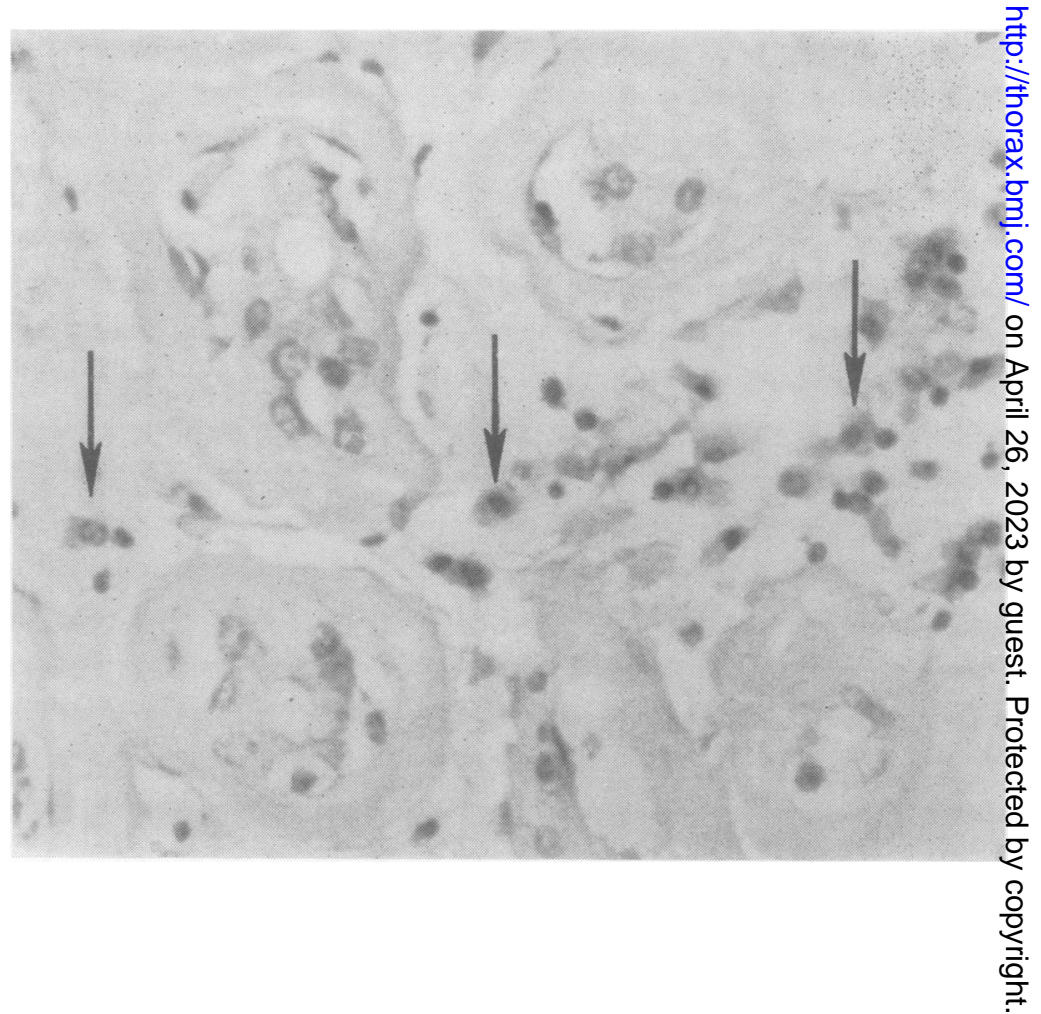




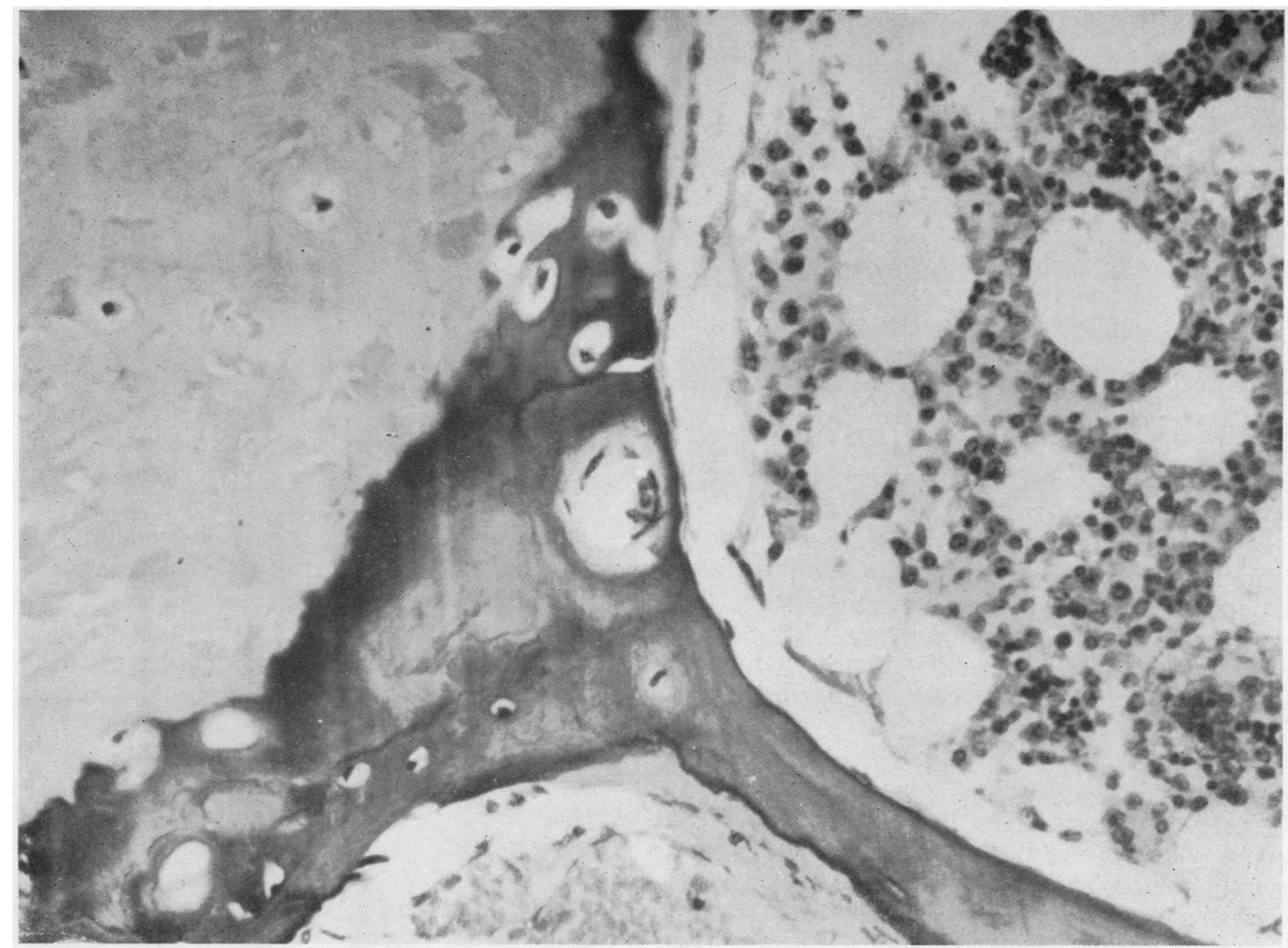

FIG. 5. A focus of bone formation with haemopoietic marrow (right) is seen lying in the bronchial amyloid (left). $H$. and $E ., \times 280$.

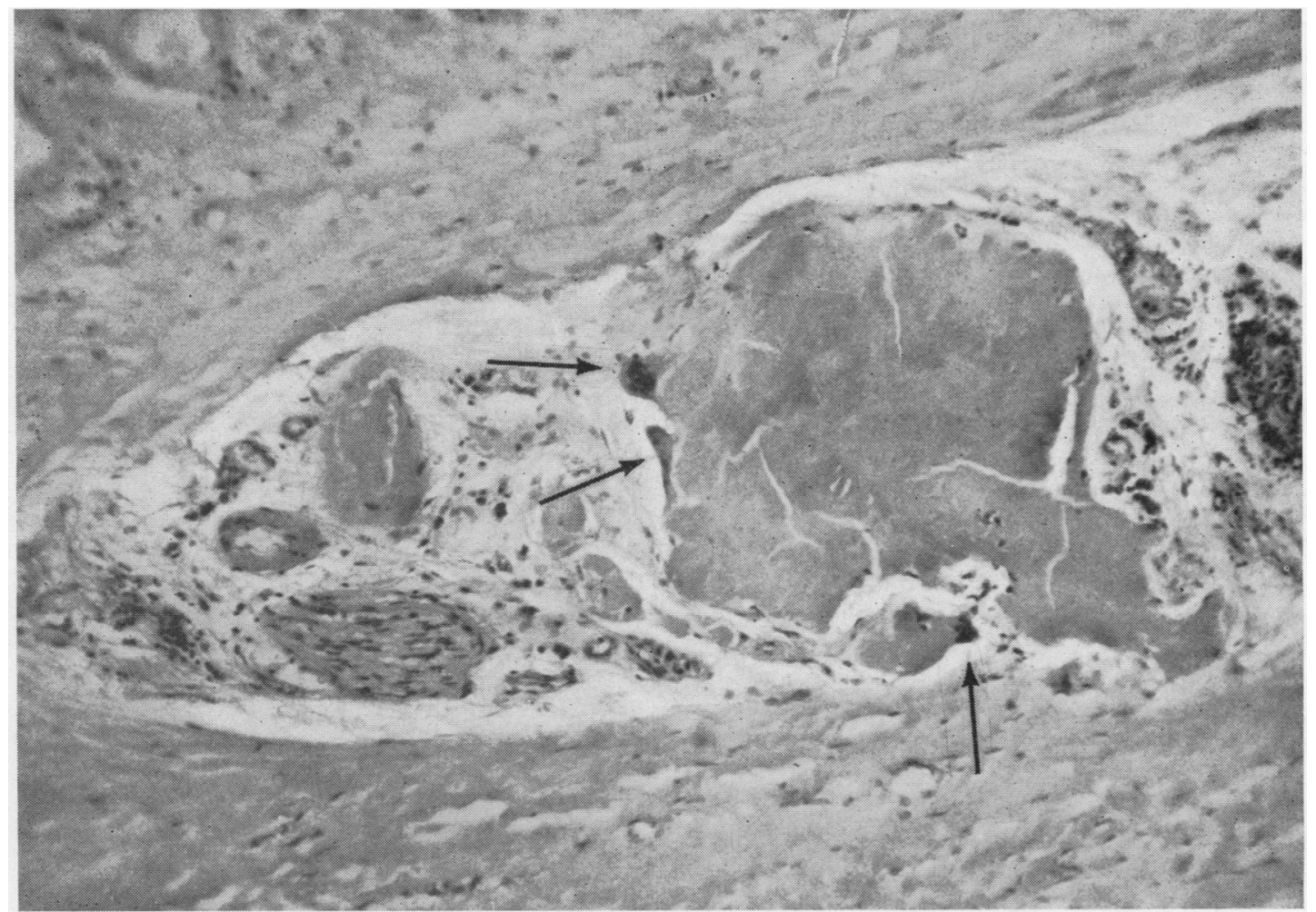

fIG. 6. An outlying amyloid deposit in the adventitial connective tissue of the bronchial wall. Giant cells are seen to the left of the main mass and also on its under surface. $H$. and $E ., \times 125$. 
Fifty blocks of tissue from lungs, larynx, trachea, bronchi, heart, adrenal, liver, pancreas, spleen, stomach, bladder, breast, oesophagus, kidney, blood vessels, tongue, uterus, bone marrow, thyroid, ureter, and vagina were subjected to the closest histological scrutiny with the double object of confirming the nature of the deposits in the larynx, trachea, and main bronchi, and excluding the presence of amyloid elsewhere. Particular attention was paid to the blood vessels, nerves, lymph nodes, and connective tissues forming parts of these organs. No amyloid deposits were found in any situation other than the larynx, trachea, and main bronchi, and the tissues immediately investing them: this was a striking demonstration that the changes remained specifically localized in spite of having been present for more than 10 years.

Histologically, the bronchial epithelium was intact and the amyloid was deposited in the greatly thickened submucosa. The number of functional mucous glands was much reduced, many being converted into amyloid 'ghosts'. The process of conversion, best seen in the transition zone adjacent to normal bronchial tissues, appeared to begin in the basement membrane, the epithelium thinning out and disappearing as this membrane thickened progressively (Fig. 4). The amyloid was not a continuous sheet but was intersected by loose connective tissue septa containing vessels and small clumps of fat storage cells; in these septa there was patchy infiltration by small round cells, including a high proportion of plasma cells (Fig. 4). The veins were dilated and their walls were free from amyloid ; in contrast, the arterioles generally were narrowed and bore thick sheaths of amyloid; some vessels affected in this way could be traced into the adventitial connective tissue outside the cartilaginous portion of the bronchial wall. The submucosal amyloid masses between the septal intersections stained variably and were often irregular in shape; they extended outwards to the bronchial rings, with which they sometimes appeared to fuse, and also penetrated between them to lie as irregular scattered masses in the adventitial connective tissue. Calcification and ectopic foci of bone were common, the latter containing marrow which was frequently haemopoietic (Fig. 5). A prominent feature was the presence of multinucleated giant cells apparently ingesting the amyloid, particularly in the neighbourhood of bone foci and in the outlying deposits (Fig. 6).

The impression produced was one of continuous remodelling, rather than inert deposition, of amyloid. The plasma cells were never found in situations which demonstrated active amyloid formation, but they were sufficiently widespread to make us think that they might be concerned in the process.

\section{DISCUSSION}

Typical (secondary) amyloidosis became less common as the incidence of chronic sepsis declined, but forms of the disease then emerged which had not previously been recognized. Classification into primary and secondary types and further subdivision of the former into that associated with myelomatosis, as well as tumourforming varieties both local and diffuse, has done nothing to clarify the 'amyloid problem'. On the contrary, this classification and regionalization has tended to separate the varieties and to imply that each has its own identity, whereas a common cause for all types, modified in its effects by existing local or general conditions, would be more in keeping with experience of other equally protean diseases. Symmers (1956a) expressed a similar opinion in his review of primary amyloidosis. In this paper we have reconsidered the aetiology of amyloidosis in the light of our further experience and that of others recorded in recent publications, and suggest a common cause for all forms of this disease.

Clinically, the typical (secondary) and primary types have been observed to overlap, and Glauser (1955), who described a case of his own with nodular pulmonary deposits, pointed out that in this variety every transition has been seen, from the submucous deposits of Balser (1883), von Werdt (1908), and Noring and Paaby (1952), and more recently Gordon (1955), Prowse (1958), and Dood and Mann (1959), to the gross amyloid tumours of Holle (1940), Lunzenauer (1952), Meyer (1911), Weismann, Clagett, and McDonald (1947), Haynes, Clagett, and McDonald (1948), and Schmidt, McDonald; and Clagett (1953). Lunzenauer (1952) states that tumours may occur in typical (secondary) or atypical (primary) amyloidosis, and that they may be single, multiple or associated with diffuse deposits with or without recognizable predisposing disease. Wolpert (1920) and Holle (1940) have also described amyloid tumours in cases of typical (secondary) amyloidosis. Furthermore, Glauser (1955) stated that the manner of formation is similar in all types by deposition initially in the walls of supplying blood vessels.

Calkins, Cohen, and Larsen (1960) restated an opinion already expressed by Symmers (1956a) 
when they wrote that 'differentiation of primary from secondary amyloidosis should at present depend on the absence of underlying disease known to predispose to this condition', but this probably does not go far enough, and it might be more correct to assume that all forms are 'secondary' to a single predisposing cause. Symmers (1956b) observed deposits typical of secondary amyloidosis in the absence of a predisposing cause in one case and those of primary amyloidosis in two cases with chronic suppuration. In one of his two cases associated with rheumatic fever the distribution was characteristic of primary amyloidosis, and in the other, of secondary amyloidosis. Calkins and his associates (1960) found that deposits in eight cases of secondary and nine of primary amyloidosis were chemically, anatomically, and structurally similar and that serum hexosamine and gamma globulin values were raised in both. They subscribed to the view held by Mellors and Ortega (1956) and by Vazquez and Dixon (1956) that amyloid is an antigen-antibody precipitate though they themselves failed to prove this.

Weiss (1960) described a case with multiple amyloid nodules and a 'plasmacytoid lymphoma' in the same lung; he reviewed the records of 14 cases of isolated nodular pulmonary amyloidosis previously described and noted the hypothesis of Battaglia and Masini (1957) that amyloid might result from a localized allergic reaction. He referred to Glauser's (1955) case and to those of Schottenfeld, Arnold, Gruhn, and Etess (1951), which he thought bridged the gap between isolated nodular amyloidosis and nodular pulmonary involvement in generalized amyloidosis. He referred also to the role of plasma cells which were present but scanty in his case, and to the possible relation of the plasmacytoid lymphoma to the other pulmonary deposits because of the known connexion between lymphocytes, plasma cells, and the production of antibody (Fagraeus, 1948), and the possible association of this process with amyloid deposition in all its forms.

Magnus-Levy (1931, 1933), Apitz (1940a, b, c), Teilum (1948a, b ; 1952). Randerath $(1947,1948)$, and Heilmeyer (1942) have all seen a connexion between plasma cells, hyperproteinaemia, and amyloid deposition. Hyperproteinaemia is seen in its most extreme form in myelomatosis, but it has also been shown to be progressive in chronic suppuration (Jacobi and Grayzel, 1945) up to the time of amyloid deposition; likewise a fall from a previously raised serum protein level precedes the appearance of amyloid experimentally
(Letterer, 1949). Hyperproteinaemia has sometimes been noted (Calkins et al., 1960 ; Symmers, $1956 \mathrm{~b}$ ) in cases of primary systemic amyloidosis in the probable absence of myelomatosis but has not been recorded with the localized tumourforming variety; plasmacytosis has not invariably been observed though it has sometimes been an outstanding feature (Glauser, 1955). From what is known of the insidious development and prolonged, often symptomless, course of these conditions until a late stage, we may expect a return to normal from a previously high serum protein level at the time of deposition as in the typical (secondary) and experimental forms. It is significant, moreover, that a fall has been observed in amyloidosis complicating myelomatosis and that in this condition the distribution of the deposits is characteristically that of the primary systemic type.

Fagraeus (1948) has shown that plasma cells are formed from cells of the reticulo-endothelial system during antibody production. The gamma globulin fraction contains this antibody, and Teilum (1952) has noted hypergammaglobulinaemia in a number of conditions including myelomatosis, hyperimmunity in animals, and experimental amyloidosis, for which he postulates an allergic pathogenesis and which he considered to be due to noxious stimulation of the reticuloendothelial system and the immunity mechanism.

Kennedy (1962) used sulphur 35 as a tracer to study the synthesis and deposition of amyloid experimentally and, by combining the previous hypotheses of Virchow (1858) and of Teilum (1952), suggested a theory for its pathogenesis. He thought that circulating glycoprotein, which might be the product of an immune process, combined with mucopolysaccharide, produced locally by the vascular endothelial cells under the stimulus of increased capillary permeability, to form insoluble amyloid. Undoubtedly the association between plasmacytosis, hyperproteinaemia, and amyloid deposition is significant, but whether an immune process is also involved remains unproven. Kennedy hinted that it might play a part though this was not a necessary tenet for his thesis. His tracer experiments have in any case shown how the ingredients of amyloid can be brought together and the finished product made to appear.

It is less easy to understand how the same principles may apply in the case of localized amyloid deposits, whether diffuse or nodular, but plasma cells have been noted in the vicinity of nodular deposits (Glauser, 1955 ; Weiss, 1960) and are to be seen in sections from the present case. 
These could be a source of glycoprotein (antibody), produced in response to antigen stimulation locally, and available there for combination with mucopolysaccharide to form isolated or regional amyloid deposits. Mellors and Ortega (1956) have demonstrated proteins, of the type known to include antibodies, locally in the glomerular lesions of renal amyloidosis.

In spite of variations in the constitution and disposition of amyloid deposits, the case for a similar pathogenesis in all varieties is strong. The clinical types merge one with another; hyperproteinaemia has been demonstrated in all but the purely local forms, and cannot yet be excluded in these as an earlier unobserved event. Whether or not an immune process is also involved remains doubtful, but, if it is, the occurrence of strictly localized deposits, particularly when hyperproteinaemia is not observed, becomes easier to explain.

Thorough necropsy examination in a number of the recorded cases of diffuse tracheo-bronchial amyloidosis has shown that the deposits are strictly localized to the trachea and large bronchi. In the case described here the search for amyloid elsewhere was exhaustive, and it is almost certain that there were no deposits in other parts of the body.

Bronchiectasis, which was a striking feature in the present case, is well known as a precursor of typical (secondary) amyloidosis, but has not previously been described in its present association. If there is a common predisposing cause for all types of amyloid disease and if this acts through the immunity mechanism, as has been suggested, then possibly in the diffuse tracheo-bronchial variety a source of antigen may exist locally in the respiratory tract. The bronchiectasis observed in this patient could not have been such a source because radiographs of the chest were normal in 1949 when symptoms, afterwards found to be due to tracheo-bronchial amyloid deposits, were already present. On the other hand, collapse of the lower lobes of both lungs was observed from time to time during succeeding years and that on the right side was notably persistent. It therefore seems likely that in this patient the amyloid deposits, by producing chronic bronchial obstruction, were a cause and not an effect of bronchiectasis.

Alternatively, bronchial infection, recurrent over many years, has been noted in most of the recorded cases including this one and could be a source of antigen locally. The rarity of diffuse tracheo-bronchial amyloidosis may be in sharp contrast to the prevalence of chronic bronchitis, but this does not exclude the latter as a local source of antigen, and such a source would be in keeping with the strict localization of amyloid in these rare cases.

It could be that the differing forms of amyloidosis observed represent modifications of the same process dependent upon variations in the site, strength, duration, and frequency of the antigen stimulus and the antibody response which this provokes, thus: (1) strictly localized deposits from weak focal stimulation (localized amyloidosis, including the diffuse tracheo-bronchial variety); (2) abundant deposits, particularly in the reticuloendothelial and excretory systems (spleen, liver, and kidneys), from vigorous stimulation long continued, generally in young subjects (secondary amyloidosis) ; (3) fine but more diffuse deposits, from prolonged stimulation of intermediate force, usually in older subjects (primary amyloidosis); or (4) any combination or permutation of the other three.

\section{SUMMARY}

A patient with diffuse tracheo-bronchial amyloidosis is described; brief clinical details supplement those published in a previous report (Prowse, 1958) and are followed by an account of the necropsy findings and the histological appearances at the site of amyloid deposition. The literature is reviewed and arguments are advanced in favour of a common aetiology for amyloidosis in all its forms. If this acts through the immunity mechanism, it is suggested that variations in the site, strength, duration, and frequency of the antigen stimulus and in the antibody response may determine the nature and distribution of the amyloid deposits.

We wish to thank Mr. S. T. Higgins, clinical photographer to the Brighton and Lewes Hospitals Group, for his willing cooperation and the skill with which he has photographed the pathological material.

\section{REFERENCES}

Apitz, K. (1940a). Die neuen Auschauungen vom Plasmocytom des Knochenmarks, dem sog. multiplen Myelom. Klin. Wschr., 19, 1025 .

(1940b). Die Störungen des Eiweissstoffwechsels bei Plasmo- N cytomträgern. Ibid., 18, 1058.

(1940c). Die Paraproteinosen. Virchows Arch. path. Anat., 306, 631.

Balser, W. (1883). Tracheo- und Bronchostenose mit Amyloid in der Wandung der Luftwege. Ibid., $1,67$.

Battaglia, S., and Masini, T. (1957). Paramiloidosi neoplastiforme del $\mathbb{D}$ polmone e del fegato e suoi rapporti con le enzimopenie eredi- :tarie. Folia hered. path. (Milano), 6, 79.

Calkins, E., Cohen, A. S., and Larsen, B. (1960). Amyloidosis: preliminary clinical, chemical, and experimental observations. Ann. N.Y. Acad. Sci., 86, 1033 .

Dood, A. R., and Mann, J. D. (1959). Primary diffuse amyloidosis of the respiratory tract. A.M.A. Arch. Path., 67, 39.

Fagraeus, A. (1948). Antibody production in relation to the develop- 2 ment of plasma cells. Acta med. scand., 130, Suppl. 204. 
Glauser, O. (1955). Uber tumorförmiges Amyloid in den Lungen. Schweiz. Z. allg. Path. 18, 42.

Gordon, W. (1955). Amyloid deposits in the bronchi. Brit. med. J., 1, 825.

Haynes, A. L., Clagett, O. T., and McDonald, J. R. (1948). Tumorforming amyloidosis of the lung. Report of a case. Surgery, 24, 120

Heilmeyer, K. (1942). Die Tumorbildungen des RES (b) Das Myelom. In Handbuch der inneren Medizin, 3rd ed., ed. G. von Bergmann and R. Staehelin, Vol. 2, p. 509. Springer, Berlin.

Holle, G. (1940). Beitrag zum Amyloidproblem. Beitr. path. Anat., $105,49$.

Jacobi, M., and Grayzel, H. (1945). Generalized secondary amyloidosis. J. Mt Sinai Hosp., 12, 339.

Kennedy, J.S. (1962). Sulphur 35 in experimental amyloidosis. J. Path. Bact., 83, 165.

Letterer, E. (1949). Some new aspects of experimental amyloidosis. Ibid., 61, 496

Lunzenauer, K. (1952). Uber Amyloid-"Tumoren" der Lungen. Frankfurt. Z. Path., 63, 519 .

Magnus-Levy, A. (1931). Bence-Jones-Eiweiss und Amyloid. Z. klin. Med. 116, 510

(1933). Multiple Myelome. VII. Ibid., 126, 62.

Mellors, R. C., and Ortega, L. G. (1956). New observations on the pathogenesis of glomerulo-nephritis, lipid nephrosis, periarteritis nodosa, and secondary amyloidosis in man. Amer. J. Path., 32, 455

Meyer, O. (1911). Utber lokales tumorartiges Amyloid in den Lungen. Frankfurt Z. Path., 8, 304.

Noring, O., and Paaby, H. (1952). Diffuse amyloidosis in the lower air passages. Acta path. microbiol. scand., 31, 470

Prowse, C. Barrington (1958). Amyloidosis of the lower respiratory tract. Thorax, 13, 308 .

Randerath, E. (1947). Zur pathologischen Anatomie der sog. Amyloidnephrose. Virchows Arch. path. Anat., 314, 388.
(1948). Utber die Morphologie der Paraproteinosen. Verh. dtsch. Ges. Path. $32,27$.

Schmidt, H. W., McDonald, J. R., and Clagett, O. T. (1953). Amyloid tumors of the lower part of the respiratory tract and mediastinum. Ann. Otol. (St. Louis), 62, 880.

Schottenfeld, A., Arnold, L. M., Gruhn, J. G., and Etess, A. D. (1951). Localized amyloid deposition in the lower respiratory tract. Amer. J. Med. 11, 770.

Symmers, W. St. C. (1956a). Primary amyloidosis: a review. J. clin. Path., 9, 187.

(1956b). Amyloidosis. Ibid., 9, 212.

Teilum, G. (1948a). Allergic hyperglobulinosis and hyalinosis (paramyloidosis) in the reticulo-endothelial system in Boeck's sarcoid amyloidosis) in the reticulo-endothelial system

- (1948b). Hyperglobulinemia, periarterial fibrosis of the spleen, and the wire loop lesion in disseminated lupus erythematosus in relation to allergic pathogenesis. Ibid., 24, 409.

- (1952). Cortisone-ascorbic acid interaction and the pathogenesis of amyloidosis, Ann, rheum. Dis., 11, 119.

Vazquez, J. J., and Dixon, F. J. (1956). Immunohistochemical analysis of amyloid by the fluorescence technique. J. exp. Med., 104, 727.

Virchow, R. (1858). Die Cellularpathologie, Lecture XVII. Amyloide Degeneration. Entzuindung. Hirschwald, Berlin. Eng. trans. by F. Chance (1860). Cellular Pathology, pp. 367-384. Churchill, London.

Von Werdt, F. (1908). Lokales Amyloid im gesamten Respirationstrakt. Beitr. path. Anat., 43, 239.

Weismann, R. E., Clagett, O. T., and McDonald, J. R. (1947) Amyloid disease of the lung treated by pneumonectomy. $J$. thorac. Surg., 16, 269.

Weiss, L. (1960). Isolated multiple nodular pulmonary amyloidosis. Amer. J. clin. Path., 33, 318.

Wolpert, J. (1920). Beitrag zur Kenntnis der metastasierenden Amyloidtumoren. Virchows Arch. path. Anat., 227, 173. 